\title{
Impact of pulsed electric field and pulsed microwave treatment on morphological and structural characteristics of sunflower seed ${ }^{\text {is }}$
}

\author{
Ivan A. Shorstkii ${ }^{1,{ }^{*}, \mathrm{a}}$, Alexey G. Zherlicin ${ }^{2}$ and Peifeng $\mathrm{Li}^{3}$ \\ ${ }^{1}$ Department of Technological equipment and Process Engineering, Kuban State University of Technology, Krasnodar, Russian \\ Federation \\ ${ }^{2}$ Radiation and Plasma Technologies Laboratory, Tomsk Polytechnic University, Tomsk, Russian Federation \\ 3 School of Engineering, University of Glasgow, Glasgow, United Kingdom
}

Received 23 July 2019 - Accepted 17 October 2019

\begin{abstract}
This paper presents the morphological capillary-porous structure analysis of sunflower seed, using X-ray microtomography in the longitudinal and transverse section and FESEM analysis of the surface microstructure after novel technologies treatment. Two types of treatment are considered: pulsed electric field treatment that has electroporation effect of the oil cell structure and pulsed microwave treatment that affects the internal structure. The main characteristic of the capillary-porous structure of oil-bearing material is given. Air cavities in the structure of the sunflower kernels were observed using X-ray microtomography. The influence of a pulsed electric field treatment on structure integrity of sunflower cells has been obtained with the creation of a material that has a greater permeability for diffusion processes. Experimentally was determined that over 2500 electric pores were formed on an area of $1 \mathrm{~cm}^{2}$ as a result of a pulsed electric field treatment. In the case of a pulsed electric field treatment, the oil seed body model can be represented as a bidispersed structure with the addition micro capillaries, formed by an electric field. It was experimentally defined that pulsed microwave treatment affected of internal seed structure. Denaturation of proteins and breakage of oil globules after pulsed microwave treatment decreased dispersion of the sizes of particles approximately twice with $35.3 \mu \mathrm{m}^{2}$ up to $18.1 \mu \mathrm{m}^{2}$. The data obtained are of interest not only for the technology of processing oilseeds but also for the analysis of novel emerging technologies.
\end{abstract}

Keywords: microscopic analysis / microtomography / structure / sunflower seed / pulsed electric field / pulsed microwave

\begin{abstract}
Résumé - Impact du traitement par champ électrique puis par micro-ondes pulsées sur les caractéristiques morphologiques et structurelles des graines de tournesol. Cet article présente l'analyse morphologique de la structure capillaro-poreuse de la graine de tournesol, en utilisant la microtomographie à rayons $\mathrm{X}$ en coupe longitudinale et transversale et une analyse FESEM (Field Emission Scanning Electron Microscopy) de la microstructure de surface après un traitement par de nouvelles technologies. Deux types de traitement sont envisagés : le traitement par champ électrique pulsé qui a un effet d'électroporation de la structure de la cellule oléifère et le traitement par micro-ondes pulsé qui affecte la structure interne. La principale caractéristique de la structure capillaro-poreuse de l'oléagineux est donnée. Des cavités d'air dans la structure des amandes de tournesol ont été observées par microtomographie à rayons X. L'influence d'un traitement par champ électrique pulsé sur l'intégrité de la structure des cellules a été obtenue grâce à la création d'un matériau offrant une plus grande perméabilité aux processus de diffusion. Expérimentalement, il a été déterminé que plus de 2500 pores électriques se formaient sur une surface de $1 \mathrm{~cm}^{2}$ à la suite d'un traitement par champ électrique pulsé. Dans le cas d'un traitement par champ électrique pulsé, le modèle du corps de la graine oléagineuse peut être représenté sous la forme d'une structure bi-dispersée avec addition de micro-capillaires créés par un champ électrique. Il a
\end{abstract}

\footnotetext{
"Contribution to the Topical Issue "Sunflower / Tournesol".

*Correspondence: i-shorstky@mail.ru

${ }^{a}$ Present address: 2 Moskovskaya Street, 350072 Kranodar, Russian

Federation.
} 
été défini expérimentalement que le traitement par micro-ondes pulsées affectait la structure interne de la graine. La dénaturation des protéines et la rupture des oléosomes après un traitement par micro-ondes pulsées ont diminué la dispersion des tailles de particules de l'ordre d'un facteur 2, de $35,3 \mu \mathrm{m}^{2}$ à $18,1 \mu \mathrm{m}^{2}$. Les données obtenues présentent un intérêt non seulement pour la technologie de traitement des graines oléagineuses, mais également pour l'analyse de nouvelles technologies émergentes.

Mots clés : analyse microscopique / microtomographie / structure / graine de tournesol / champ électrique pulsé / micro-onde pulsée

\section{Introduction}

Novel emerging technologies such as pulsed microwave and pulsed electric field treatments might increase the speed and efficiency of oil production during oil extraction and oil pressing. Knowledges of capillary and porous structure, oil droplets and cells sizes in combinations with structural changes during different treatment technologies played an important role in food processes design (Puértolas and Barba, 2016; Shorstkii et al., 2017; Budnikov and Vasiliev, 2018).

Pulsed microwave and pulsed electric field treatment technologies actively take root into a production cycle of oil crops processing at material preparation stages, and during processing. Most of the recently researches reported high efficiency of pulsed electric field treatment at preliminary preparation stages of oil crops (Barba et al., 2015; Sarkis et al., 2015). Many reports have demonstrated the advantages of PEF and microwave application for oil seeds. This includes good extraction efficiency as well as obtaining a good oil quality (Bakhshabadi et al., 2018, 2017). Teh et al. (2015) developed a pulsed electric field and microwave treatment method for polyphenols extraction from canola seed cake. It was found that the microwave pretreatment time of 5 minutes with electromagnetic power of $633 \mathrm{~W}$ is an optimum condition for microwaveassisted extraction. Puértolas and Martínez de Marañón (2015) treated olive seeds by pulsed electric field to allow better extraction yield and chemical parameters. It was found that pulsed electric field treatment significantly increased the extraction yield by $13.3 \%$ and total tocopherols significantly higher than control. Choi et al. (2006) reported, that microwave radiation affected the microstructure of soybean cells pronouncedly, thereby increasing the extraction of soluble soy protein. SEM-images demonstrated a significantly difference between treated and untreated soybean structure. After microwave treatment, it was found that the protein bodies inside the cell wall were extracted outside.

However, the main problem of understanding treatment mechanism is insufficiency of knowledge of morphological capillary-porous material structure changes after treatment. Components of widespread oil crops such as rapeseed, linseed and sunflower seed have various properties and can differently react to the treatment technology. Internal changes analysis is a challenge for better process design.

For the last ten years, the three-dimensional computer microtomography becoming more actively used in the food industry for the analysis of various cultures of soy seed, linseed and rapeseed (Hu et al., 2013; Rocha et al., 2014). During microtomography analysis, such parameters as oil yield, protein content or percentage of a protective skin in seeds can be determined. One of the widespread directions of microtomography application is the analysis of seeds viability and activity (Dudak et al., 2016).
A variety of the practical tasks solved on the basis of methods and means of a microtomography both of the purpose and contents, and on the conditions, allows solving a problem of the analysis of an internal morphology of material by means of various physical methods. Correctly the number of research works and research methods applying introscopy, in that number an X-ray tomography are, not enough, and researches are limited only to a micro focal X-ray analysis and samples up to $2 \mathrm{~mm}$ thick with use of methods of mercury pyrometry (Schoeman et al., 2016).

Recent study Taghvaei et al. (2015) has revealed that microwave can destroy the structure of oil cells during the process and facilitate the oil extraction without any heat treatment. Hence, with pretreatment of microwave-assisted extraction, there is no need to roast the oilseeds before extraction, which could have a potential benefit for the industry.

This work is directed to data acquisition of morphological capillary-porous structure of sunflower seeds before and after pulsed microwave and pulsed electric field treatment using an $\mathrm{X}$-ray microtomography and electronic microscopy.

\section{Materials and methods}

In this study used sunflower seed cultivar Richard (Lider), which was kindly provided by a local factory (Russia, Krasnodar region). Initial oil content of seeds was $56.07 \pm 0.28 \%$.

The microscopic analysis of a seeds surface was carried out with scanning electronic microscope (SEM) JEOL SEM 6360LA (A*Star, IMRE, Singapore), that allows investigate the surface of material without additional operations of preparation.

\subsection{X-ray microtomography}

The X-ray microtomography (XMT) $60 \mathrm{kV}$ and $35 \mu \mathrm{A}$ together with SEM was applied to characterize the internal morphology of sunflower seed kernel. The voxel size was about $10 \mu \mathrm{m}$. The studied seeds were not exposed to additional processing before the analysis. For the analysis, five samples of seeds were taken. During the tomographic scan that is conducted in air and at room temperature, kernel was rotated around the vertical axis. From the variations in the phase of the beam, better sensitivity of compositional changes in the seed structure was observed. Focusing was carried out on those sites of the structure of a seed kernel which had the most contrast structure. Because the refractive index of a material for hard $\mathrm{X}$-rays is directly related to its electron density, the result is a $3 \mathrm{D}$ representation of the local electron density. 

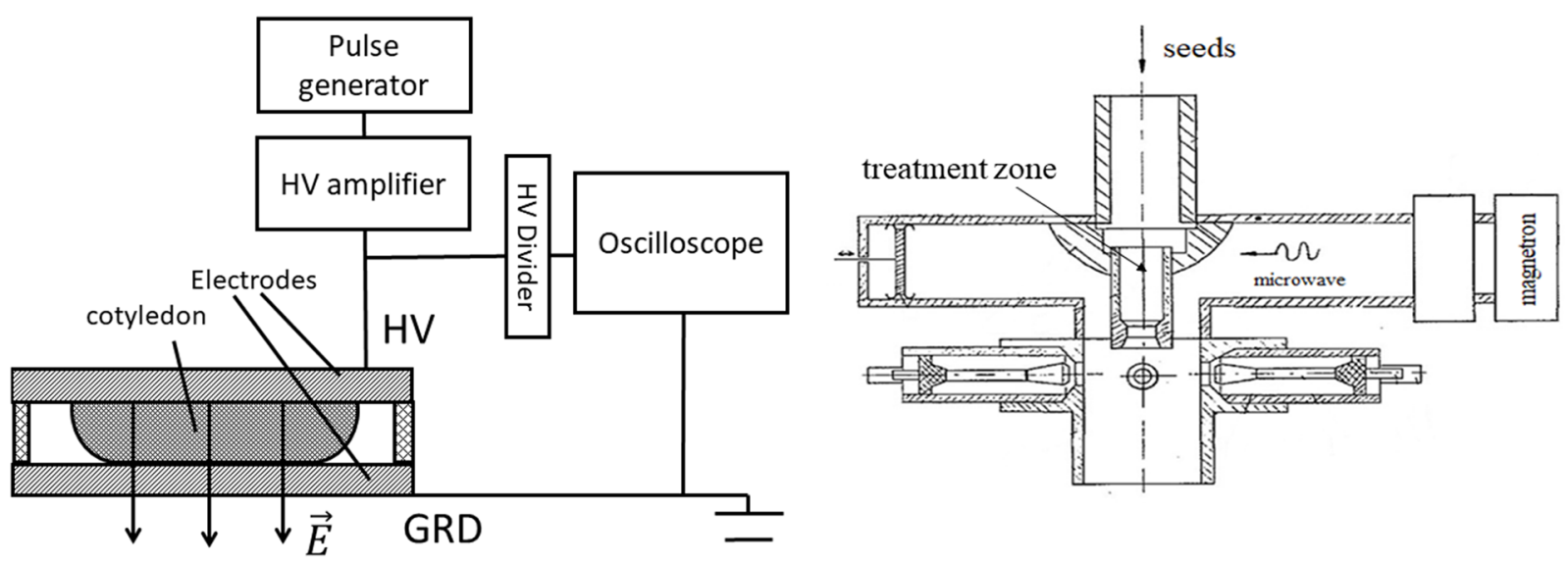

Fig. 1. Pulsed electric field treatment setup (left) pulsed microwave setup (right).

\subsection{Pulsed electric field and microwave treatment}

Disintegration of the sunflower cells membrane was carried out due to its electroporation mechanism. Due to the pulse nature of electric field, the loaded ions under the influence of the force of electric field escape from the structure of olive cells in the direction of the enclosed electric field. For carrying out processing, the cotyledon of sunflower kernel was placed in the processing cell by pulse electric field (Fig. 1) and soaked in a salted water. The functional Agilent 33220A generator (Agilent Technologies, USA) created positive electric impulses of rectangular type lasting $10 \mu \mathrm{s}$, then the amplifier of tension Trek COR-A-TROL 610D (TREK Inc, Lockport, USA) amplified on amplitude up to the voltage of $15 \mathrm{kV}$. For digitization and quality control given on processing of impulses the oscilloscope of Tektronix TDS 220, with an additional high-voltage divider was used $(400 \mathrm{MHz}, \mathrm{x} 1000)$.

Pulsed microwave treatment was carried out in pulsed microwave setup (Tomsk Polytechnic University) with shielded treatment chamber showed in Figure 1. Microwave plasma torch with $3.5 \mathrm{~kW}$ output energy was used. The setup produced a radial discharge initiation, within $60 \mathrm{~s}$. After the treatment all samples were cooled down to the room temperature.

\subsection{Treatment process modeling}

QuickField (TeraAnalysis Ltd, Denmark) software was used to determine the most effected treatment zone of pulsed electric field on sunflower seed. Electric field strength $E=15 \mathrm{kV} / \mathrm{cm}$ in chamber with two opposite titanium electrodes. The electrode conductivity $\sigma=2.8 \cdot 10^{6} \mathrm{~S} / \mathrm{m}$ and material conductivity $\sigma=0.28 \mathrm{~S} / \mathrm{m}$ placed between electrodes were used as input data.

\section{Results and discussion}

\subsection{Microtomography}

Figure 2 shows the microtomographic images of the structure: general view, cross and longitudinal cut of a sample of a sunflower kernel. In large parts of the kernel (Fig. 2a), in connection with insignificant heterogeneity of structure,

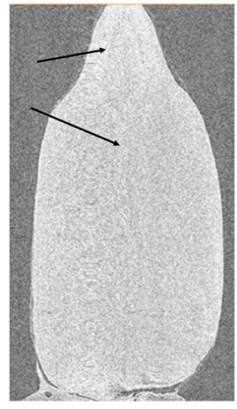

a

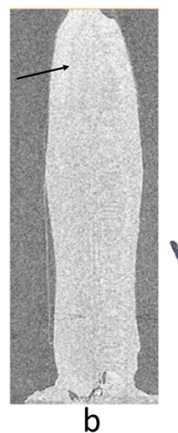

b

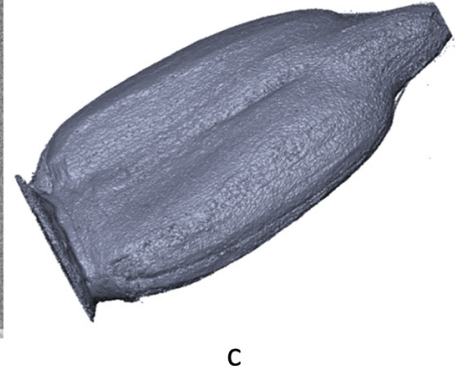

C
Fig. 2. Transverse section (a) and longitudinal section (b) of sunflower kernel and cain view of the sunflower kernel obtained on X-ray microtomography (c).

thanks to XMT air chambers in the top part of a kernel (pro-cambium zone) noted by an arrow are defined. We suggest that this zone contains spare oxygen, as the regulating mechanism in order to avoid an anoxia in seeds.

The XMT method gives the chance to accurately present external morphology of 3D structure of a kernel in which the volume and the area can be calculated (Fig. 3). Differences in attenuation in X-ray beams when passing through the structure to the first turn depend on the thickness and density of the material, density of membranes of cells and contents.

Unlike an atomic magnetic resonance (AMR), XMT allows to visualize dry objects as it can get into more dense beds of material and depends on the general contrast of density, but not on moisture content (Windt and Blümler, 2015). However, the use of XMT is infeasible in real time (in vitro) due to the radioactivity of the X-ray.

The microscopic analysis of the structure of sunflower seeds shows distinct nuclear fission on two cotyledons which have a rather dense structure and high accretion of a seed.

Figure 3 shows the morphological structure of sunflower seeds. In a kernel cotyledon, the arrangement of cells has orderly character, cells of the cylindrical extended form, are characterized by distinctly expressed lipidic spherosome and proteinaceous globule diffuse located in a volume of cells and united by a cytoplasmic matrix. Turgor pressure forces lipid spherosomes toward a spherical form. 


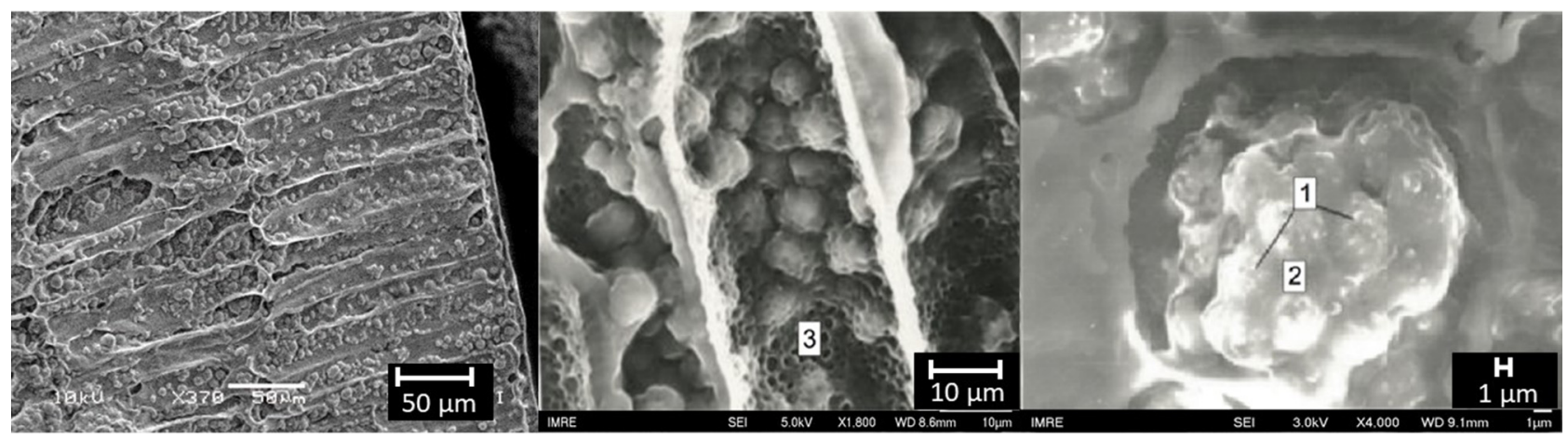

Fig. 3. An internal structure of sunflower seeds cells with transverse (a) and longitudinal (b) section, $U=10 \mathrm{kV}$, increased $\mathrm{x} 450$ and $\mathrm{x} 370$ times: 1-lipid spherosomes; 2- cytoplasmic matrix, 3-cell membrane.

Figure 3 also shows an orientation of a long axis of cellsradial, packing rather dense. The thickness of a sowing layer averages 50 microns, and the palisade occupies more than a half of width of a seed layer. The size of cells of a sunflower kernel is from 100 to 200 microns in length and from 10 to 60 microns wide. Oil bodies have a spherical shape from 0.2 to 6 microns in size with the majority of oil bodies of a diameter less than 2 microns. However, different results were reported previously for same seed cultivar by (Nikiforidis et al., 2013) in which the dimension of cells for the studied grade were from 650 to 850 microns long and from 200 to 300 microns wide.

It was observed that sunflower seed existence of micropores, mesopores, and super micropores, with an average size from $500 \mathrm{~nm}$ to $75 \mu \mathrm{m}$. Pores form varies from the circle to cavities of a various geometry form (Fig. 4) and it depends on seeds varieties. It should be noted that the main technological properties of the material such as diffusive permeability, hydrodynamic resistance filtering ability, the development of an internal surface and sorption properties in the defining degree depend on characteristics of the capillary and porous structure of a kernel.

\subsection{Impact of pulsed electric field on the surface structure}

According to the previous work (Le Clef and Kemper, 2015) more than $40 \%$ spherosomes are not destroyed after crushing and moisture-thermal treatment during industrial processing of sunflower seeds that limits a residual oil yield in a meal. Impact of PEF on a cotyledon of sunflower seed was carried out with electrical parameters: electric field strength $E=15 \mathrm{kV} / \mathrm{cm}$, number of pulses $n=3600$ and pulse duration $10 \mu \mathrm{s}$. Considering that vector lines of electric field represent the equipotential distribution of the field (Fig. 5), the peak value of tension of the field of $15 \mathrm{kV} / \mathrm{cm}$ is on $1 / 4$ high from upper electrode. For further analysis a cotyledon was cut at this height.

Figure 6 shows the structure of a surface of a cotyledon of sunflower after PEF treatment. Change of integrity of the structure of sunflower cells with the destruction of a membrane is clearly noticeable. At more approximate image electric breakdowns on a surface of cells in the form of convex craters, less than 1 micron in size is noticeable. It was experimentally defined that on the area of $1 \mathrm{~cm}^{2}$ more than 2500 electric time is

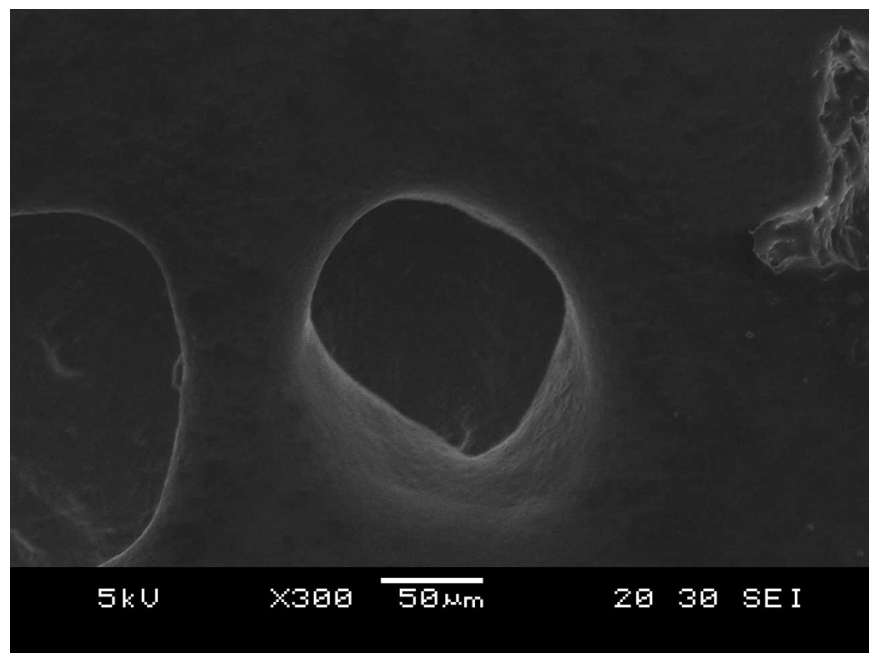

Fig. 4. Single pore on the surface of the sunflower kernel.

located (Fig. 6b). Two models of the creation of porous bodies-capillary and globular are presented in literature (Tovbin, 2017). The simplest capillary model is the set through, not reported among themselves cylinders of a capillary radius. The most part of sunflower materials should be carried to bodies of the capillary model. In case of processing by pulse electric field, the model of sunflower body can be presented in the form of a capillary model with capillary and electroporated channels. We made attempt to expand the model of the bidisperse structure with the addition of the micro capillaries formed due to an influence of electric field. Using such input data model of mass transfer processes in sunflower seeds can be described.

\subsection{Pulsed microwave impact on crops structure}

Pulsed microwave radiation gets into the structure of the material and interacts with polar molecules by means of the ionic conductivity and dipolar rotation which are followed by heat generation. For sunflower material moisture, salts and proteins act as the dipolar material perceiving the microwave radiation.

The field and frequency $(2450 \mathrm{MHz})$ are constant for industrial radiation microwave oven, the only varied parameter 


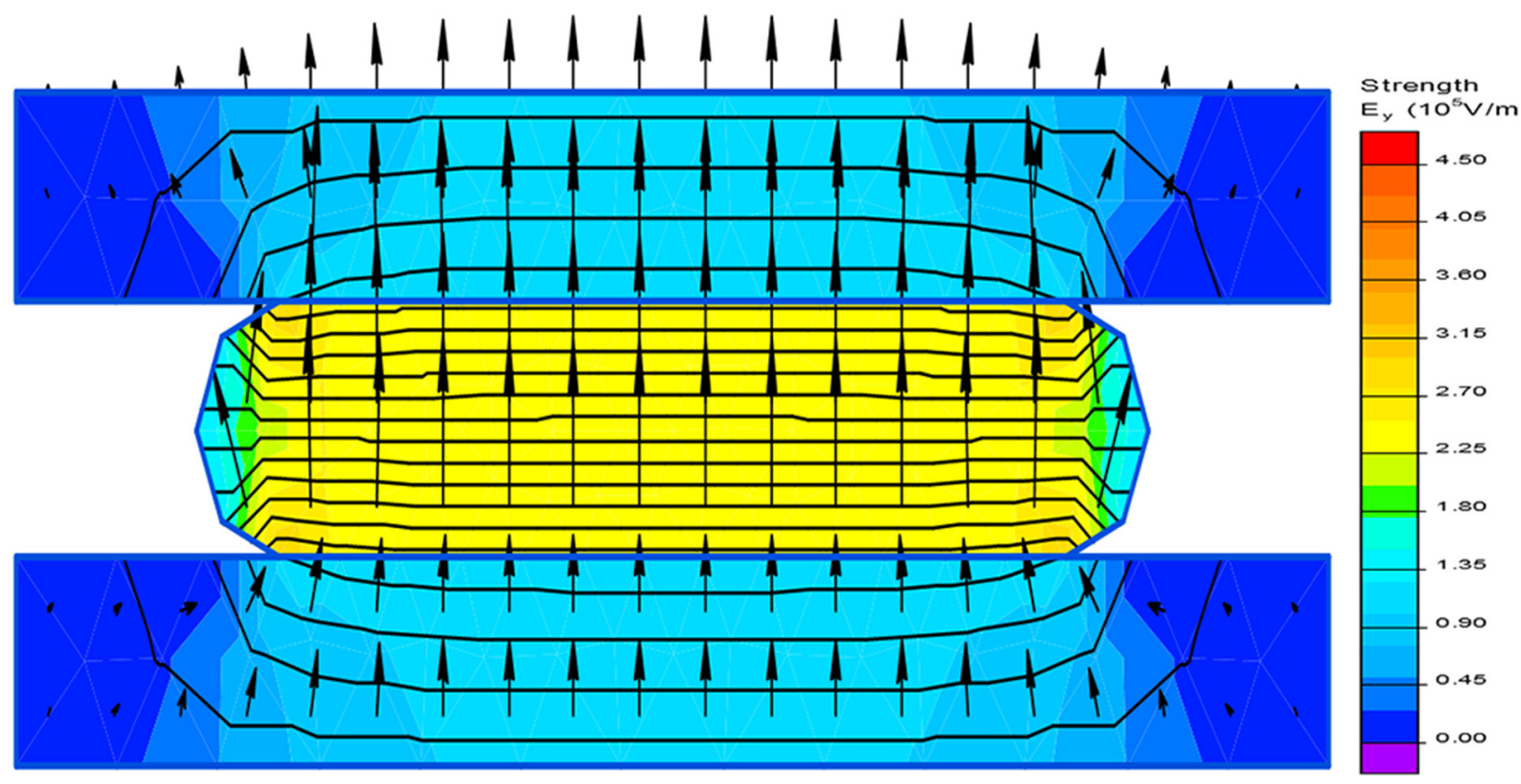

Fig. 5. Simulation of the distribution of the field strength at the moment of the pulse discharge $t=9.48 \mathrm{e}^{-18} \mathrm{~s}$.

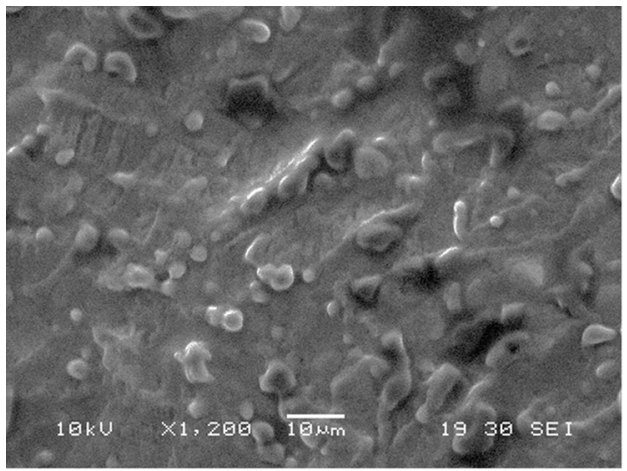

(a)

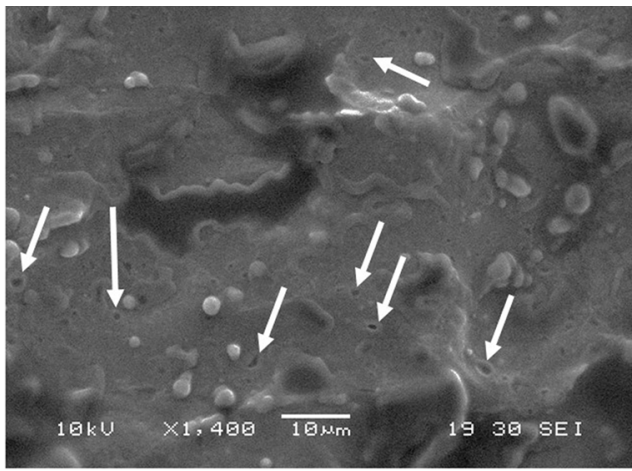

(b)

Fig. 6. Sunflower cotyledon surface after pulsed electric field treatment increased: x1200 (a) and x1400 (b) times.

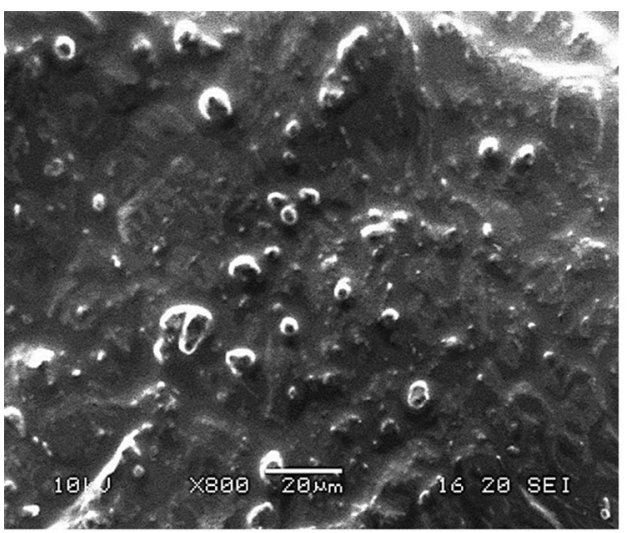

(a)

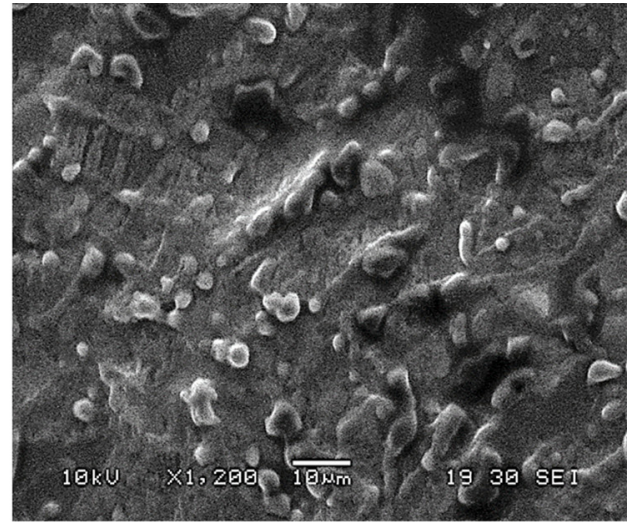

(b)

Fig. 7. Sunflower kernel surface structure before microwave treatment (a) and after microwave treatment (b). 
of processing is the coefficient of dielectric losses $\varepsilon$ ”. Dielectric losses of sunflower seeds (Shorstkii et al., 2015) is defined the extent of heating by the humidity of $7 \%$ up to $105^{\circ} \mathrm{C}$. Figure 7 shows sunflower kernel surface structure of after pulsed microwave treatment with a power of $3.5 \mathrm{~kW}$ within 1 minute. Using internal Jeol program, it was defined that dispersion of the sizes of particles after microwave heating decreased approximately twice with $35.3 \mu \mathrm{m}^{2}$ up to $18.1 \mu \mathrm{m}^{2}$. This decrease is caused by the formation of the uniform structure of sunflower material, a possible denaturation of proteins and breakage of oil globules.

At the same time particles agglomerates sizes depends on the initial content of humidity in seeds and pulsed microwave treatment duration. Thus, identification of an optimum condition of the pulsed microwave heating of sunflower material can promote its effective processing in the course of pressing or extraction. A great number of authors tested microwave-heating methods. So in work (Koubaa et al., 2016) increase in an exit of oil of soy at pressing stages at $10 \%$ after the preliminary microwave oven of processing within $1600 \mathrm{~W}$ minute is noted. In work (Bakhshabadi et al., 2017) increase in oil yield of Black cumin seeds after microwave treatment at up to $15 \%$ is noted. In case of aggregation of particles in the course of pulsed microwave treatment the porous body can be formed at the expense of bodies, close to spherical shape, i.e. it can be presented as a globular model of a body. The sizes and arrangement proteinaceous globules when processing characterizes durability of the received deformed particles. Combinations of different technologies such as pulsed microwave treatment and pulsed electric field treatment can create a new model of a porous olive body. This task put forward into our further work.

The results presented here show structural details in the sunflower seed kernels after PEF and pulsed microwave treatment that were not observed before. We suggest that the air space network in sunflower seeds, visualized through the nondestructive approach of quantitative phase tomography, provides a transport system for easy gas exchange in embryos and serves as storage space for the oxygen that will be needed at the onset of germination. In addition, sunflower body after PEF treatment can be presented in the form of a capillary model with capillary and electroporated channels. PEF and pulsed microwave treatment technologies for oilseeds processing can be as well optimized to be scaled up to industrial level. The design of this process can be economically optimized to take further internal structure modifications into account.

\section{Conclusion}

X-ray microtomography in combination with SEM and FESEM analysis provided a detailed information of internal structure of sunflower seed. Experimentally air cavities inside sunflower seed were observed. This air cavities contains spare oxygen, as the regulating mechanism in order to avoid an anoxia in seeds. Pulsed electric field and pulsed microwave treatment significantly influence on internal structure of sunflower seed. As a great tool for electroporation mechanism PEF created more than 2500 electric pores on the area of $1 \mathrm{~cm}^{2}$. The size of such pores are less than 1 micron. Due to structural changes after PEF treated oil body can be presented as a capillary-porous bidisperse structure with the addition of the micro capillaries formed due to an influence of electric field. Pulsed microwave treatment has another great mechanism, which cause the aggregation of particles in the course of treatment. Experimentally it was observed that dispersion of the particle sizes after pulsed microwave treatment decreased approximately twice with $35.3 \mu \mathrm{m}^{2}$ up to $18.1 \mu \mathrm{m}^{2}$. Due to structural changes after pulsed microwave treatment, oil body can be presented as a globular model due to an influence of electromagnetic fields. Obtained information of microstructural parameters of sunflower seed: cell dimension, orientation, average porous size etc. can be used for process design of novel electrical technologies. With the expansion of the allowing ability, the X-ray microtomography has a high potential for new opportunities of a qualitative and quantitative research of external and internal morphology of oil-bearing crops with more detailed consideration of processes of the influence of physical forces at the cellular level. The obtained data represent interest not only for a technology of processing of sunflower seed but also for the analysis of new emerging technologies.

Acknowledgments. The reported research was funded by Russian Foundation for Basic Research and the government of the region of the Russian Federation, grant No 18-38-00448.

\section{References}

Bakhshabadi H, Mirzaei H, Ghodsvali A, Mehdi S, Mohammad A, Farzaneh V. 2017. The effect of microwave pretreatment on some physico-chemical properties and bioactivity of Black cumin seeds' oil. Ind Crops Prod 97: 1-9. https://doi.org/10.1016/j. indcrop.2016.12.005.

Bakhshabadi H, Mirzaei H, Ghodsvali A, Mahdi S, Aman J, Ziaiifar M. 2018. The influence of pulsed electric fields and microwave pretreatments on some selected physicochemical properties of oil extracted from black cumin seed. Food Sci Nutr, 111-118. https:// doi.org/10.1002/fsn3.535.

Barba FJ, Boussetta N, Vorobiev E. 2015. Emerging technologies for the recovery of isothiocyanates, protein and phenolic compounds from rapeseed and rapeseed press-cake: Effect of high voltage electrical discharges. Innov Food Sci Emerg Technol, 6-11. https://doi.org/10.1016/j.ifset.2015.06.008.

Budnikov D, Vasiliev A. The use of microwave energy at thermal treatment of grain crops. In: Kharchenko V, Vasant P, eds. Handbook of research on renewable energy and electric resources for sustainable rural development. Hershey, PA, USA: IGI Global, 2018, pp. 475-499. https://doi.org/10.4018/978-1-5225-3867-7. ch020.

Choi I, Choi SJ, Chun JK, Moon TW. 2006. Extraction yield of soluble protein and microstructure of soybean affected by microwave heating. J Food Process Preserv 30(4): 407-19. https://doi.org/10.1111/j.1745-4549.2006.00075.x.

Dudak J, Zemlicka J, Karch J, et al. 2016. High-contrast X-ray microradiography and micro-CT of ex-vivo soft tissue murine organs utilizing ethanol fixation and large area photon-counting detector. Sci Rep 6: 1-9. https://doi.org/10.1038/srep30385.

Hu ZY, Hua W, Zhang L, et al. 2013. Seed structure characteristics to form ultrahigh oil content in rapeseed. PLoS ONE 8(4): 2-11. https://doi.org/10.1371/journal.pone.0062099. 
Koubaa M, Mhemdi H, Barba FJ, Roohinejad S, Greiner R, Vorobiev E. 2016. Oilseed treatment by ultrasounds and microwaves to improve oil yield and quality: An overview. Food Res Int 85: 5966. https://doi.org/10.1016/j.foodres.2016.04.007.

Le Clef E, Kemper T. 2015. Sunflower seed preparation and oil extraction. Sunflower, 187-226. https://doi.org/10.1016/ B978-1-893997-94-3.50014-3.

Nikiforidis CV, Kiosseoglou V, Scholten E. 2013. Oil bodies: An insight on their microstructure-Maize germ vs. sunflower seed. Food Res Int 52(1): 136-141. https://doi.org/10.1016/j.foodres.2013.02.052.

Puértolas E, Barba FJ. 2016. Electrotechnologies applied to valorization of by-products from food industry: Main findings, energy and economic cost of their industrialization. Food Bioprod Process 100: 172-184. https://doi.org/10.1016/j.fbp.2016.06.020.

Puértolas E, Martínez de Marañón I. 2015. Olive oil pilot-production assisted by pulsed electric field: Impact on extraction yield, chemical parameters and sensory properties. Food Chem 167: 497-502. https://doi.org/10.1016/J.FOODCHEM.2014.07.029.

Rocha CRM, da Silva VN, Cicero SM. 2014. Internal morphology and germination of sunflower seeds. J Seed Sci 36(1): 48-53. https://doi.org/10.1590/s2317-15372014000100006.

Sarkis JR, Boussetta N, Tessaro IC, Marczak LDF, Vorobiev E. 2015. Application of pulsed electric fields and high voltage electrical discharges for oil extraction from sesame seeds. J Food Eng 153: 20-27. https://doi.org/10.1016/j.jfoodeng.2014.12.003.
Schoeman L, Williams P, du Plessis A, Manley M. 2016. X-ray microcomputed tomography $(\mu \mathrm{CT})$ for non-destructive characterisation of food microstructure. Trends Food Sci Technol 47: 10-24. https://doi.org/10.1016/j.tifs.2015.10.016.

Shorstkii I, Koh XQ, Koshevoi E. 2015. Influence of temperature and solvent content on electrical properties of sunflower seed cake. $J$ Food Process Preserv 39(6). https://doi.org/10.1111/jfpp.12574.

Shorstkii I, Mirshekarloo MS, Koshevoi E. 2017. Application of pulsed electric field for oil extraction from sunflower seeds: Electrical parameter effects on oil yield. J Food Process Eng 40 (1). https://doi.org/10.1111/jfpe.12281.

Taghvaei M, Jafari SM, Nowrouzieh S, Alishah O. 2015. The influence of cooking process on the microwave-assisted extraction of cottonseed oil. J Food Sci Technol 52(2): 1138-1144. https://doi.org/10.1007/s13197-013-1125-5.

Teh S, Niven BE, Bekhit AEA, Carne A, Birch EJ. 2015. Microwave and pulsed electric field assisted extractions of polyphenols from defatted canola seed cake. Int J Food Sci Technol 50: 1109-1115. http://dx.doi.org/10.1111/ijfs.12749.

Tovbin YK. The moleculat theory of adsorption in porous solids. CRC Press, 2017, 780 p. https://doi.org/10.1201/9781315116297.

Windt CW, Blümler P. 2015. A portable NMR sensor to measure dynamic changes in the amount of water in living stems or fruit and its potential to measure sap flow. Tree Physiol 35(4): 366375. https://doi.org/10.1093/treephys/tpu105.

Cite this article as: Shorstkii IA, Zherlicin AG, Li P. 2019. Impact of pulsed electric field and pulsed microwave treatment on morphological and structural characteristics of sunflower seed. OCL 26: 47. 